\title{
O CARM. 1.3 DE HORÁCIO, DUAS TRADUÇÕES DE ELPINO DURIENSE E DUAS IMITAÇÕES QUINHENTISTAS ${ }^{1}$
}

\author{
Alexandre Pinheiro Hasegawa* \\ Recebido em: 31/03/2020 \\ Aprovado em: 03/06/2020
}

RESUMO: Neste artigo pretendo discutir a presença do Carm. 1.3 de Horácio nas letras portuguesas, em particular em duas traduções de Elpino Duriense e duas imitações quinhentistas, uma de Antônio Ferreira (Odes 1.6) e outra de Luís de Camões em Os Lusiadas (4.102-4), no discurso do Velho do Restelo. Apesar de algumas críticas à composição horaciana como a de um poeta imaturo, parece que o poema teve importante fortuna, já na Antiguidade, e de maneira particular no séc. XVI português. As imitações quinhentistas tiveram sua fortuna nas letras portuguesas e Elpino Duriense considera a de Antônio Ferreira em uma de suas traduções.

PALAVRAS-CHAVE: Horácio; Odes 1.3; tradução; Elpino Duriense; Antônio Ferreira; Camões.

HORACE'S ODES 1.3, ELPINO DURIENSE'S TWO TRANSLATIONS, AND TWO PORTUGUESE IMITATIONS OF THE SIXTEENTH CENTURY
* Professor de língua e literatura latina, Faculdade de Filosofia, Letras e Ciências Humanas, Universidade de São Paulo.

ahasegawa@usp.br 
scholars, the poem was translated into Portuguese since the sixteenth century and imitated since Antiquity. Some Portuguese imitations stand out in Portuguese Literature and Elpino Duriense has that of Antônio Ferreira as a model for one of the two translations.

KEYWORDS: Horace; Odes 1.3; translation; Elpino Duriense; Antônio Ferreira; Camões.

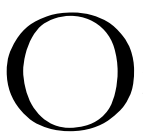

Carm. 1.3 de Horácio teve apreciação muito variada ao longo do tempo. A começar pelos poetas antigos, encontramos, pelo menos, três alusões ao texto horaciano: Ovídio, em Am. 2.11; Sêneca, em Med. 301-8; Estácio, em Silv. 3.2. ${ }^{2}$ Parece, portanto, que a ode era bem conhecida e, por ser emulada, foi considerada modelar. A posição de destaque, colocada na primeira sequência decimal, chamada modernamente Parade Odes (1.1-10), ${ }^{3}$ certamente favoreceu o poema, que tem como personagem o poeta e amigo Virgílio, responsável por introduzi-lo no círculo de Mecenas. ${ }^{4}$ Depois do Carm. 1.1, em que se dirige a Mecenas (v. 1), e do Carm. 1.2, em que louva Mercúrio-Otaviano (vv. 41-52), surge Virgílio, mais de uma vez elogiado por Horácio, alma pura a que o poeta está muito afeiçoado. ${ }^{5}$ No entanto, entre alguns filólogos modernos ${ }^{6}$ - nomes importantes

${ }^{2}$ Para o propemptikon de Estácio a Mécio Céler, ver Putnam (2017), em que aponta, sobretudo, o diálogo com a Eneida, mas não deixa de mencionar Carm. 1.3 (p. 89; p. 130, n. 10); Cairns (1972, p. 234ss.) compara com Silv. 3.2; Nisbet-Hubbard (1970, p. 41-2), ao fazer uma "história" do propemptikon, menciona Ovídio e Estácio (p. 41), anotando as imitações específicas nos comentários aos versos e palavras (p. 45-58); para a imitação de Sêneca, por exemplo, ver Hine (2000, p. 147ss.), Németi (2003, ad loc.), Mayer (2012, p. 75) e Boyle (2014, p. 209ss.); McKeown (1998, p. 222ss.), mencionando Nisbet-Hubbard e Cairns, mostra como Ovídio em Am. 2.11 se insere na tradição do propemptikon, anotando os paralelos com Horácio. Fedeli (1980, p. 205), por sua vez, considera, com razão, Ov. Am. 2.11 mais imitação de Propércio 1.8a.

${ }^{3}$ Para discussão da sequência inicial de Odes 1, ver síntese das propostas em Minarini (1989, p. 25-6), que resume os estudos sobre a organização de Odes 1 (26-100). Julgamos que, embora Horácio não apresente todas as possibilidades métricas até Carm.1.10, a sequência decimal apresenta a variedade de metros, que se confronta com a alternância do início do segundo livro (2.1-11) e a monometria do terceiro (3.1-6). Importa, a nosso ver, para delimitar a seção inicial, a primeira repetição métrica, com a estrofe sáfica, e o estabelecimento do falso fim em 1.10 (ver Hasegawa, 2017, p. 92-5).

${ }^{4}$ O próprio Horácio relata em Sat. 1.6.54-5 que foi apresentado, primeiramente, por Virgílio e depois por Vário: "nulla etenim mihi te fors obtulit: optimus olim / Vergilius, post hunc Varius, dixere quid essem". ${ }^{5}$ Encontramos o elogio na passagem citada anteriormente, em que o qualifica como optimus (Sat. 1.6.54); além disso, na viagem a Brundísio, elogia Virgílio, ao lado de Plócio e Vário, por sua candida anima (Sat. 1.5.40-42): "Plotius et Varius Sinuessae Vergiliusque / occurrunt, animae qualis neque candidiores / terra tulit neque quis me sit devinctior alter".

${ }^{6}$ Pasquali (1920, p. 262): "questa lirica pare a me delle meno felici" (ver ainda p. 267; 273); NisbetHubbard (1970, p. 45): “... we miss Horatian virtues of brevity and incisiveness [...]. The poem may have been written early, when Horace was still trying to surmount the technical difficulties of writing Latin lyrics [...]", Romano (1991, p. 481), mencionando Pasquali, diz: "l'enfasi e lo stile concettoso e arguto inducono piuttosto a ritenerla un componimento giovanile" (ver ainda nota ao v. 1, p. 482). Fraenkel (1957), surpreendentemente, não a comenta. 
que já muito contribuíram para o estudo de Horácio -, a ode não pareceu bem composta, obra de poeta ainda imaturo. Há evidentemente dissenso neste julgamento do Carm. 1.3 entre os estudiosos. ${ }^{7} \mathrm{O}$ objetivo, porém, deste artigo não é tomar posição numa disputa, por vezes, subjetiva, de gosto pessoal em relação à ode horaciana. Propomo-nos a discutir duas traduções de Elpino Duriense e duas imitações quinhentistas, a de Antônio Ferreira, em suas Odes (1.6), e a de Camões, em Os Lusíadas (4.102-104), que evidenciam a fortuna do poema nas letras portuguesas e como, por vezes, a tradução incorpora imitações do poema traduzido.

Veremos, primeiramente, a tradução de Elpino Duriense, nome árcade de Antônio Ribeiro dos Santos, publicada em 1807, em que propõe a translação literal das Odes e Epodos, censurando partes ou poemas inteiros. ${ }^{8}$ Porém, reproduzimos, antes de mais nada, o texto original latino estampado na referida edição, com as notas em que o poeta-tradutor explica as escolhas das várias edições ${ }^{9}$ compulsadas para o estabelecimento do texto, o que mostra, primeiramente, cuidadosa leitura do original:

$$
\begin{aligned}
& \text { Ad navim Virgilii }{ }^{10} \\
& \text { Sic te Diva potens Cypri, } \\
& \text { sic fratres Helenae, lucida sidera, } \\
& \text { ventorumque regat pater, } \\
& \text { obstrictis aliis praeter Iapyga, }
\end{aligned}
$$

\footnotetext{
${ }^{7}$ Cairns (1972, p. 232) cita as críticas de Nisbet-Hubbard para, na sequência (p. 234-5), se contrapor com os mesmos termos usados pelos últimos; termos italicizados por nós: "The effect is not charming - Horatian odes can have other virtues - but it is highly relevant way, and through its reticence, its selectivity in the use of topoi, and its implicit mode of conveying information, displays admirable brevity and incisiveness".

${ }^{8}$ Sobre a tradução de Elpino Duriense e os poemas censurados, ver Hasegawa (2015).

${ }^{9}$ Uma das edições mais citadas com lições ainda hoje discutidas é a do filólogo inglês Richard Bentley (1662-1742), que publicou, pela primeira vez, em 1711 (Cambridge). Houve, porém, nova edição em 1713 e 1728 (Amsterdam). Não sabemos exatamente qual a consultada por Elpino Duriense. A edição do filólogo escocês Alexander Cunningham (1655-1730), que rivalizava com a de Bentley, publicada em 1721 (Londres), é outra muito referida. Entre as francesas, destaca-se a do padre jesuíta NoëlÉtienne Sanadon (1676-1733), que publica a edição completa, em 1728 (Paris), com tradução francesa. A edição do acadêmico renascentista Daniel Heinsius (1580-1655), grafado como Heinsio, que publica em 1629 (Leiden) as obras de Horácio com comentários, é outra muitas vezes mencionada. Como se veem nas notas, Elpino se serve de muitas outras edições, demonstrando grande conhecimento delas e dos comentários à obra de Horácio, raramente encontrados em outras traduções portuguesas contemporâneas, como a de José Agostinho de Macedo (1761-1831), publicada um ano antes daquela de Elpino, que, embora conheça algumas edições, não tem a preocupação que vemos aqui de discutir o texto latino. Sobre a diferença entre José Agostinho de Macedo e Elpino Duriense como tradutores de Horácio, ver Hasegawa (2012).

${ }^{10}$ Sobre os tituli nos manuscritos e nas edições modernas, embora não horacianos, ver Tarrant (2019, p. 319).
} 
navis, quae tibi creditum

debes Virgilium, finibus Atticis

reddas incolumem, precor,

et serves animae dimidium meae.

Illi robur et aes triplex

circa pectus erat, qui fragilem truci

commisit pelago ratem

primus, nec timuit praecipitem Africum

decertantem Aquilonibus,

nec tristis Hyadas, nec rabiem Noti;

quo non arbiter Hadriae

major, tollere seu ponere volt freta.

Quem mortis timuit gradum, qui siccis oculis ${ }^{11}$ monstra natantia,

qui vidit mare turbidum et

infamis scopulos Acroceraunia?

Nequicquam Deus abscidit

prudens Oceano dissociabilis ${ }^{12}$

terras, si tamen inpiae

non tangenda rates transiliunt vada.

Audax omnia perpeti, gens humana ruit per vetitum nefas. ${ }^{13}$

Audax Japeti genus

ignem fraude mala gentibus intulit.
5

\footnotetext{
${ }^{11}$ [N. do T.]: A lição vulgar diz siccis oculis: João Dryden, Gualtieri e Heinsio nas notas a Valério Flaco, Liv. V, v. 827, e depois deles Bentley repõem rectis oculis; Cunningham emenda fixis oculis, seguido de Sanadon; nós conservamos a lição vulgar, não nos fazendo maior peso as razões em contrário.

${ }^{12}$ [N. do T.]: Bentley quer que se leia dissociabiles terras, como sendo as que Deus não queria que se unissem entre si, dividindo-as e separando-as pelos mares de permeio, porque os homens se contentassem de seu próprio terreno. Já antes dele assim leu Gualtieri ao Liv. I. C. 38 da Obra das Memórias de Pancirolo, Heinsio nas notas a Valério Flaco, Lib. I, v. 827, e Porte, que na tradução Francesa refere este adjetivo para terras. Baxter, Gesnero, Sanadon e Combe com a lição vulgar põem dissociabili.

${ }^{13}$ [N. do T.]: Seguimos a lição ordinária per vetitum nefas, posto que João Duhamel, autorizado por um antigo Ms., e depois dele Sanadon, com uma ligeira mudança, emendem per vetitum et nefas, querendo que estes dois termos não sejam sinônimos, mas encerrem em duas classes todo o gênero de crimes, isto é, o que era vedado pelas leis civis, vetitum, e o que o era pelas leis naturais, nefas. Esta emenda havemos por mais engenhosa que necessária, sendo muito ordinário nos poetas ajuntar a um termo, que diz mais, um epíteto, que diz menos, ou que não era ali absolutamente preciso, e isto ou em razão da medida do verso ou por alguma outra circunstância particular.
} 


\author{
Post ignem aetheria domo \\ subductum, Macies et nova Febrium \\ terris incubuit cohors: \\ semotique prius tarda Necessitas \\ leti corripuit gradum. \\ Expertus vacuum Daedalus aëra \\ pennis non homini datis. \\ perrupit Acheronta Herculeus labor. \\ Nil mortalibus arduum ${ }^{14}$ est; \\ caelum ipsum petimus stultitia; neque \\ per nostrum patimur scelus \\ iracunda Jovem ponere fulmina.
}

30

40

Das três notas de Elpino Duriense para o texto latino, a primeira ao v. 18 (siccis oculis) e a terceira ao v. 26 (vetitum nefas) seguem a "lição vulgar", como fazem os comentários e edições mais modernos. No entanto, ainda hoje se comenta a conjectura de Bentley (rectis oculis), mas apenas para rejeitá-la. Porém, para o v. 22 (prudens Oceano dissociabilis) o tradutor português deixa a "lição vulgar" (dissociabili), em que o adjetivo caracteriza Oceano, para relacioná-lo, como faz Bentley, com terras (v. 23). A lição, contudo, não teve grande fortuna e a mais conservadora (dissociabili) é, em geral, a adotada nas edições modernas. De fato, parece não haver necessidade de correção do texto transmitido, já que a incompatibilidade indicada pelo adjetivo dissociabilis ("incompatível") pode ser atribuída tanto a um como a outro.

$\mathrm{Na}$ primeira tradução, nos lugares de disputa do texto, o tradutor oferece versão alternativa, caso se escolha a lição não adotada por ele. Por vezes, apresenta mais de uma alternativa para o mesmo trecho, como é o caso dos vv. 21-23 da ode aqui analisada: "Indo pela lição vulgar diremos: Em vão próvido Deus com o Oceano / insociável separou as terras. Ou: Debalde co'Oceano insociável / prudente retalhou as terras Jove". Não se encontra, em geral, essa preocupação de dar tradução para lições ou conjecturas não adotadas pela edição, algo que também distingue o trabalho de Elpino Duriense dos demais tradutores.

O texto latino segue ao lado da tradução, que reproduzimos na sequência:

Ao navio de Virgílio

Assim a Deusa poderosa em Chipre, assim os irmãos d'Hélena, brilhantes astros, e o rei dos ventos, só co’ Jápis, prendendo os mais, te reja,

\footnotetext{
${ }^{14}$ Elpino não comenta a preferência pela variante arduum. Todas as outras edições consultadas trazem ardui, modernamente a opção mais aceita. O comentário de Nisbet-Hubbard (1970, ad loc.) afirma que "ardui is more forceful than the variant arduum".
} 
ó nau, que és de Vergílio devedora, 5

que a ti se confiou, rogo-te, o ponhas

salvo nas terras Áticas, e guardes metade de minha alma.

Enzinho e tresdobrado bronze havia em torno ao peito quem ao pego iroso

o baixel frágil cometeu primeiro, nem já temeu o Ábrego,

co'os Aquilões brigando impetuoso,

Híadas tristes, nem de Noto a raiva, que é d'Ádria o mor senhor, ou erguer queira, ou amainar as ondas.

Que gênero temeu de morte aquele que a olhos secos viu nadantes monstros, ${ }^{15}$ que viu túrgido mar e Acroceraunos infamados cachopos?

Em vão próvido Deus com o Oceano as terras retalhou insociáveis, se contudo os baixéis ímpios trespassam os não tocandos mares. ${ }^{16}$

Audaz a sofrer tudo, a gente humana por defesas maldades se despenha; audaz a prole de Japeto às gentes com fraude iníqua o fogo

trouxe. Depois que o fogo à casa etérea se furtou, a magreza e nova tropa de febre sobreveio à terra, e o fado vagaroso da morte,

${ }^{15}$ [N. do T.]: "Seguindo a primeira emenda de Bentley, pode traduzir-se: que com direitos olhos viu nadantes monstros, e o bravo mar, e Acroceraunos. [Acrouceranos é o que está impresso]

Parecendo melhor a segunda de Cunningham, pode-se traduzir:

que com os olhos fixos viu nadantes monstros etc."

${ }^{16}$ [N. do T.]: "Indo pela lição vulgar diremos:

Em vão próvido Deus com o Oceano insociável separou as terras.

Ou:

Debalde co'Oceano insociável prudente retalhou as terras Jove." 
dantes remota, apressurou o passo.

Tentou, com penas ao mortal não dadas,

Dédalo o ar vazio; o Aqueronte

rompeu trabalho hercúleo.

Nada aos mortais é árduo: cometemos,

loucos, o mesmo céu, e não deixamos

c'os nossos crimes, que deponha Jove

os iracundos raios.

40

\section{DA TRANSLAÇÃo LITERAL}

A tradução chamada "literal" é feita em quartetos compostos por três decassílabos (heroicos ou sáficos) seguidos por um hexassílabo. No original, porém, temos dísticos ou a primeira estrofe asclepiadeia, formada por glicônico seguido por asclepiadeu menor. Contudo, se se aceita a lei de Meineke, segundo a qual todas as odes de Horácio seriam divisíveis em quartetos, como faz boa parte das edições modernas, a proposta de Elpino seria, em parte, correspondente. Seguindo o mesmo número de versos do original (40 vv.), o tradutor ainda acompanha de perto o andamento sintático desenvolvido, em geral, no espaço estrófico de quatro versos. A única exceção, no confronto com o original, é a passagem da sétima para a oitava estrofe (vv. 28-9), em que, diferentemente de Horácio, Elpino faz encavalgamento. Embora o uso não seja estranho nas Odes (e.g. Carm. 1.5.4-5; 12-13), tal fenômeno não ocorre na passagem do Carm. 1.3. Ressaltamos, por fim, antes de análise mais minuciosa da tradução, o título que se dá a cada ode na edição portuguesa, que, embora não seja horaciano, remonta já a comentadores mais antigos.

Elpino Duriense é leitor muito atento do original latino, observando na tradução a posição das palavras, as figuras e os tropos. Observam-se, por exemplo, com rigor as anáforas $^{17}$ (vv. 1-2: "assim ... / assim ...”, que traduzem: sic ... / sic ...; vv. 17-19: "que gênero ... / que a olhos ... / que viu ...", refazendo: quem mortis ... / qui siccis ... / qui vidit ...; vv. 25 e 27: "audaz a sofrer ... / audaz a prole ...", que repõem: audax omnia ... / audax Iapeti ...). Já se chamou atenção ${ }^{18}$ para a colocação particular de terras (v. 23), palavra qualificada por dissociabilis (v. 22) - na lição adotada por Elpino -, adjetivo separado por estar em verso diferente. $O$ tradutor parece observar a significativa separação ao interpor entre o substantivo ("terras") e o adjetivo ("insociáveis") o verbo retalhar ("retalhou"), tudo no mesmo verso (v. 22). A hipálage final (v. 40), com destaque para a colocação do adjetivo (iracunda) em primeira posição e o substantivo (fulmina) como conclusão, encerrando o todo, é observada no verso final da tradução: "os iracundos raios". Destaque-se ainda o uso do acento latino para "Hélena", ressaltado por coincidir com a sexta sílaba do decassílabo heroico. O nome da personagem grega é destacado no original, ocupando a posição central do verso (v. 2),

\footnotetext{
${ }^{17}$ Um juízo negativo das anáforas no Carm. 1.3 foi feito por Pasquali (1920, p. 273-4).

${ }^{18}$ Ver Nisbet (1999, p. 140), que agradece a observação de Stephen Harrison.
} 
na sequência de três perífrases para nomear: Vênus (v. 1: sic te Diva potens Cypri: "Assim a Deusa poderosa em Chipre"), os dióscuros, Castor e Pólux (v. 2: sic fratres Helenae, lucida sidera: "assim os irmãos d'Hélena, brilhantes / astros"), ${ }^{19} \mathrm{e}$ Éolo (v. 3: ventorumque regat pater. "[...] e o rei dos ventos [...]").

Não se observa, porém, a colocação dos nomes dos ventos, destacados no original em fim de versos sucessivos (vv. 12-14): Africum ("Ábrego"), o vento sudeste; Aquilonibus ("co'os Aquilões"), vento do norte/nordeste, e Noti (“de Noto"), vento do sul. Só o primeiro deles vem ao final na tradução, que é caracterizado por "impetuoso", adjetivo colocado no fim do verso seguinte (v. 13), fazendo hipérbato inexistente no original, já que temos no v. $12 \mathrm{o}$ adjetivo seguido pelo substantivo: ... praecipitem Africum. No entanto, o hipérbato na tradução de Elpino, que faz concordância de substantivo com adjetivo colocados em fins de versos subsequentes, é muito comum em Horácio. ${ }^{20}$ Também em fim de verso, no original latino, está anteriormente o vento favorável à navegação (v. 4: Iapyga), que impele da Apúlia em direção à Grécia, vento noroeste, o "Jápis", posto neste caso na mesma posição pelo tradutor.

\section{DA TRADUÇão PARAFRÁSTICA}

Dez anos depois da publicação da tradução das Odes e Epodos de Horácio, no terceiro volume das poesias do poeta português, publicado em 1817, encontram-se duas traduções de odes horacianas (Carm. 1.3 e 2.14), sob o título de "tradução parafrástica" (p. 32-7). Deixaremos por ora o Carm. 2.14, que será estudado em publicação futura, e passaremos, para o propósito deste artigo, a comparar a "translação literal" com a "parafrástica", que reproduzimos na sequência:

Assim de Chipre a Deusa soberana, assim os irmãos de Hélena, no Olimpo

claras estrelas, e o grão rei dos ventos solto somente o Japyx, pelo alto mar te levem,

ó Nau, do meu Virgílio devedora, que em depósito tens; rogo-te, o ponhas sobre as Áticas praias livre e salvo; e guardes a querida metade da minh'alma.

${ }^{19}$ À exceção da palavra "astros", Elpino segue de perto a construção horaciana que coloca cada perífrase em um verso.

${ }^{20}$ Ocorre, por exemplo, com frequência na ode anterior (Carm. 1.2): vv. 7-8: ... altos/ ... montis; vv. 27-8: ... audientem/ ... Vestam?; vv. 31-2: ... amictus,/ ... Apollo; vv. 39-40: ... cruentum/ ... hostem; para não parecer caso isolado, damos exemplos ainda no Carm. 1.9: vv. 3-4: ...geluque/ ... acuto; vv. 7-8: ... Sabinal ... diota; vv. 21-2: ... intimo/ ... angulo. Por vezes, mais raramente, acontece em início de versos subsequentes, como no nosso Carm. 1.3.32-33: semotique ... / leti [...]. 
De duro roble, ou tresdobrado bronze tinha por certo o peito seu murado, aquele, que sem custo ousou primeiro o mal seguro pinho fiar das bravas ondas;

Que não temeu nem Áfrico arrojado c’os Aquilões brigando, ou tristes Híades; nem já de Noto desabrido a fúria, que mais que todos d'Ádria os mares senhoreia.

A qual morte houve medo, o que nadantes monstros chegou ${ }^{21}$ a ver com secos olhos, a ver as ondas d'alto pego irosas e os infames cachopos da negra Acroceráunia.

Debalde Deus com suma providência c'os limites do mar, que nos separam, as terras retalhou, se trespassando

vão ímpias naus as ondas que tocar não deveram:

Tudo audaz acomete, e por maldades, que veda a Lei, precipitada corre humana geração: com fraude iníqua trouxe aos mortais o fogo o filho de Japeto.

Já desde então de lívidas doenças nova coorte se postou na terra, e a morte, d'antes vagarosa e lenta, contra a mísera gente acelerou seus passos.

Com asas, nunca aos homens concedidas, o ar vazio Dédalo tentava; e o mesmo centro do profundo Averno por meio de Aqueronte rompeu Hércules forte.

${ }^{21}$ Estampado "chogou". 
Nada aos loucos mortais, nada é difícil;

o mesmo céu insanos cometemos;

nem com nossas maldades consentimos,

que Júpiter deponha

os iracundos raios. ${ }^{22}$

A primeira - e evidente - diferença entre as duas traduções é a extensão: a parafrástica tem dez versos a mais, organizados em quintetos, formados por três decassílabos (heroicos e sáficos), seguidos por dois hexassílabos. Assim, se a tradução literal não seguia, a rigor, esquema métrico latino, havia, porém, certa correspondência, admitida a lei de Meineke; agora, contudo, os quintetos de Elpino Duriense não encontram correspondência com as estrofes líricas de Horácio. Ademais, cresce bastante o número de adjetivos: antes tínhamos, na literal, "e o rei dos ventos" para traduzir ventorumque ... pater (v. 2: “e o pai dos ventos"), mas, na parafrástica (v. 3), acrescenta "e o grão rei dos ventos"; na primeira (vv. 7-8), "e guardes / metade de minha alma" traduz, palavra por palavra, et serves animae dimidium meae (v. 8), mas, na segunda (vv. 9-10), novamente acresce adjetivo: "e guardes a querida / metade da minh'alma"; se, primeiramente, traduz (v. 9: ... robur et aes triplex) "[e]nzinho e tresdobrado bronze", substitui "enzinho" por sinônimo ("roble") e adjetiva mais uma vez (v. 11): "[d]e duro roble, ou tresdobrado bronze"; por fim, não sendo exaustivo, o v. 37 (nil mortalibus ardui est) é traduzido sem ocupar todo o verso, verbum ad verbum: “[n]ada aos mortais é árduo ...", enquanto a última versão ganha a repetição de "nada" e novo adjetivo, substituindo o mais próximo "árduo" por "difícil": "[n]ada aos loucos mortais, nada é difícil". A tradução parafrástica, portanto, afasta-se um pouco mais do original latino, ganhando em extensão e adjetivação.

Outras mudanças, porém, não aumentam o tamanho nem mesmo o número de sílabas. É equivalente, por exemplo, "brilhantes / astros" (vv. 2-3, na literal) e "claras estrelas" (v. 3), que traduzem lucida sidera (v. 2). Tais modificações nos levaram, então, a outro modelo de Elpino Duriense, mencionado na epígrafe do primeiro volume da edição das traduções das Odes e Epodos, publicados em 1807: o poeta quinhentista Antônio Ferreira, que se destacou também por imitar Horácio em suas Odes e Epístolas. A epígrafe traz esses versos de Antônio Ferreira (Cartas 1.8): “A ti leiam, grã Flaco, após ti andem / meus olhos, trás os que também te seguem.” A citação de Elpino não só mostra como o árcade conhecia o quinhentista, mas também como Antônio Ferreira é imitador do poeta latino.

\section{Da imitação quinhentista Como modelo da traduÇão de ElPino}

Vejamos, então, Odes 1.6 de Antônio Ferreira, incluída em seus Poemas Lusitanos, endereçada ao irmão e apontada já pelos comentadores como imitação de Carm. 1.3 de Horácio: ${ }^{23}$

${ }^{22}$ [N. do T.]: Esta tradução e a seguinte, por serem parafrásticas, não entraram na edição da Lírica de Horácio de 1812 substituídas outras mais literais em seu lugar.

${ }^{23}$ Earle (2000, p. 523): “Todos os comentadores notaram o paralelismo estreito entre esta e a Odes 1.3 de Horácio, dedicada a Virgílio”. Para a comparação, remetemos também a Rocha Pereira (1972, p. 46-7). 
A uma nau d'armada em que ia seu irmão Garcia Fróis

Assi a poderosa

deosa de Chipre, e os dous irmãos de Helena, claras estrelas, e o grão rei dos ventos,

segura nau, e ditosa,

te levem, e $[\mathrm{te}]^{24}$ tragam sempre com pequena

tardança aos olhos que te esperam atentos;

que meu irmão, metade

da minha alma, que como encomendado

a ti deves, nos tornes vivo, e são

do fogo, e tempestade

a que se aventurou c'o esprito ousado.

Vença à dura fortuna a boa tenção.

Quem cometeu primeiro

ao bravo mar num fraco pau a vida

de duro enzinho, ou tresdobrado ferro

tinha o peito, ou ligeiro

juízo, ou sua alma lh'era aborrecida,

dino de morte cruel no seu mesmo erro.

Esprito furioso

Que não temeu o pego alto revolvido

(entregue aos ventos, posto todo em sorte)

do sempre tempestuoso

Áfrico, nem os vaus cegos, e o temido

Cila infamado já com tanta morte!

A que mal houve medo

Quem os monstros no mar, que vão nadando,

Com secos olhos viu? Quem o céu cuberto

de triste noite, e quedo

sem defensão, c'o corpo só esperando

está a morte cruel, que tem tão perto?

Se Deus assi apartou

com suma providência o mar da terra

que a nós, os homens, deu por natureza,

como houve homem que ousou

abrir por mar caminho mais a guerra

\footnotetext{
${ }^{24}$ Provável erro de edição de Earle (2000), em que se acrescentou um "te" a mais, não encontrado em edições mais antigas, como a de 1598. Com o pronome o verso se torna hipermétrico. Para resenha da edição, remetemos a Willis (2004).
} 
qu'a paz, e a morte mais, roubo, e crueza?

Que cousas não cometes, ousado esprito humano, em mar, e em fogo contra ti só diligente, e ingenhoso?

Que já te não prometes,

des qu'o medo perdeste à morte, e em jogo tens o que de si foi sempre espantoso?

Um o céu cometeu; outro o ar vão experimentou com penas não dadas a homem; outro o mar reparte que por força rompeu.

Senhor, que tudo vês, que tudo ordenas, pera a Ti só chegarmos dá-nos arte.

Como se percebe já pelo início, o poema de Antônio Ferreira serviu de modelo para as modificações feitas por Elpino em sua tradução parafrástica do Carm. 1.3 de Horácio. Já tínhamos chamado a atenção, por exemplo, para o acréscimo do adjetivo "grão" na tradução parafrástica de Elpino (v. 3), alteração que se vê retirada do verso do poeta quinhentista, ou melhor, o verso todo é tomado de Antônio Ferreira (v. 3) pelo árcade. Da literal para a parafrástica, Elpino substituiu o verbo "reja” (v. 4), que traduz regat do original latino (v. 3), por "levem" (v. 5), verbo mais afastado em relação à morfologia, à sintaxe e à semântica. Ora, o verbo se encontra da mesma maneira na ode de Antônio Ferreira (v. 5). Fizemos notar ainda que Elpino introduz na parafrástica o adjetivo "duro", que qualifica "roble" (v. 11). Na tradução literal (v. 9), Elpino tinha escolhido o sinônimo "enzinho" para traduzir o original robur (“carvalho"; "roble’; “enzinho”), sem qualquer qualificação como aparece em Horácio. Novamente, quando se lê o poema do poeta quinhentista, encontra-se o adjetivo (v. 15): "de duro enzinho, ou tresdobrado ferro". A substituição, por fim, da tradução "brilhantes / astros" (vv. 2-3) por "claras estrelas" (v. 3) - ambas traduzindo verbum ad verbum o original latino: lucida sidera (v. 2) - de novo é motivada pela imitação de Antônio Ferreira (v. 3: "claras estrelas"). Parece claro, portanto, que Elpino, ao refazer a tradução do Carm. 1.3, olhou não só para o original, mas também para a imitação cristã ${ }^{25}$ de Antônio Ferreira.

Para considerar ainda um outro ponto em relação à tradução parafrástica, é preciso retomar outra imitação quinhentista do poema horaciano: ${ }^{26}$ a conhecida passagem do Velho

\footnotetext{
${ }^{25}$ Note-se, por exemplo, o desaparecimento de Júpiter ao final da ode, mantido por Elpino, mesmo na parafrástica. Antônio Ferreira elabora uma prece católica ao "Senhor" Deus. Por outro lado, embora apague em seu poema algumas referências mitológicas presentes em Horácio, acrescenta Cila (v. 24), tomado como masculino (v. 23: "e o temido"). Para esta inserção, ver Earle (2000, ad loc.).

${ }^{26}$ Para uma visão geral da imitatio dos autores da Antiguidade, praticada pelos autores quinhentistas, ver Soares (2018, p. 327-50), no capítulo intitulado "Génese do discurso literário e internacionalização do saber no Renascimento”, em que destaca (p. 330) a presença de Horácio com a Ars, falando de uma "tradição retórica horaciana" na formação desses autores. Sobre as várias traduções da Ars em
} 
do Restelo n'Os Lusíadas de Camões (4.94-104). A presença do Carm. 1.3 de Horácio na passagem é reconhecida desde o comentário de Manuel de Faria e Sousa, publicado em 1639, em que no comentário à estrofe 102 não só recorda o lírico latino (p. 433), mas também a passagem da Medeia de Sêneca (vv. 301-2) e Propércio 1.17.13-4. O humanista português ainda lembra da ode horaciana ao comentar a estrofe 103 (p. 436). Leiamos, primeiramente, as estrofes d'Os Lusíadas que nos interessam para este artigo (4.102-4):

"Ó maldito o primeiro que no mundo

Nas ondas vela pôs em seco lenho!

Dino da eterna pena do profundo,

Se é justa a justa lei que sigo e tenho!

Nunca juízo algum alto e profundo

Nem cítara sonora ou vivo engenho

Te dê por isso fama nem memória,

Mas contigo se acabe o nome e glória!

Trouxe o filho de Japeto do céu

$\mathrm{O}$ fogo que ajuntou ao peito humano,

Fogo que o mundo em armas acendeu,

Em mortes, em desonras - grande engano! -

Quanto milhor nos fora, Prometeu,

E quanto pera o mundo menos dano,

Que a tua estátua ilustre não tivera

Fogo de altos desejos, que a movera!

Não cometera o moço miserando

O carro alto do pai, nem o ar vazio

O grande arquitector co filho, dando

Um nome ao mar, e o outro fama ao rio.

Nenhum cometimento alto e nefando

Por fogo, ferro, água, calma e frio,

Deixa intentado a humana geração;

Mísera sorte! Estranha condição!’27

Portugal no séc. XVIII, ver Oliva Neto (2017, p. 19, n. 9), que também discute (p. 17-9) os termos 'imitação', 'reelaboração' e 'tradução', usados pelos autores do séc. XVIII. Sobre a imitação camoniana das Odes de Horácio, ver Vasconcellos (2002/3), em que mostra como Camões, na ode "Fogem as neves frias", imita os Carm. 1.4 e 4.7, odes muito semelhantes entre si. Para a imitação de Horácio em Letras portuguesas e o estudo das traduções das Odes em português, ver Achcar (1994). Por fim, para uma ampla visão da presença dos autores gregos e latinos na literatura europeia, ver o célebre Curtius (2013), publicado pela primeira vez em alemão, em 1948.

${ }^{27} \mathrm{O}$ texto é da edição de Dias (1916), que anota no início do comentário à estrofe 102 (p. 266): "[n]as est. 102-4 há reminiscências da ode $3^{\text {a }}$ do livro I de Horácio". 
A fala do Velho do Restelo é ponto de longa discussão nos estudos sobre o épico português. ${ }^{28}$ Por que Camões inseriu um discurso contra a navegação em obra que se propõe justamente a celebrar a expansão marítima portuguesa, as viagens dos portugueses por "mares nunca d'antes navegados"? Não é o propósito deste texto discutir a razão de uma fala como essa n'Os Lusíadas; interessa-nos aqui somente mostrar como o Carm. 1.3 de Horácio era muito conhecido entre os poetas quinhentistas portugueses ${ }^{29} \mathrm{em}$ vista da matéria - os perigos da navegação - e de que modo o poema aparece em Camões. Até aqui vimos traduções de Elpino Duriense e a imitação lírica de Antônio Ferreira. Agora, porém, os versos líricos são retomados em obra épica. Ora, a imitação camoniana do Carm. 1.3 em verso épico, a condenar a navegação, parece bem apropriada, se pensarmos como nas Odes horacianas a lírica se contrapõe, com frequência, à epopeia. ${ }^{30}$ Não é também novidade a mistura de um gênero em outro, como a lírica na épica, que já se encontra na Eneida de Virgílio, ${ }^{31}$ talvez o principal modelo d'Os Lusíadas. ${ }^{32}$ Porém, o início da fala do Velho do Restelo, como já anotara Manoel de Faria e Sousa, pela maldição contra o inventor da navegação, ${ }^{33}$ aproxima-se mais de Propércio (1.17.13-4) que de Horácio ou Virgílio.

A presença horaciana, porém, na passagem de Camões se dá, sobretudo, no catálogo de personagens mitológicas que cometeram ações desmedidas (4.103-104) ${ }^{34}$ De modo muito semelhante ao catálogo de Horácio, o poeta português começa com Prometeu, valendo-se da mesma perífrase do autor das Odes (1.3.27: ... Iapeti genus): “o filho de Japeto" (103.1). Além disso, "trouxe ... / o fogo ..." (103.1-2) traduz, com precisão, ignem ... intulit (1.3.28),

\footnotetext{
${ }^{28}$ Para as interpretações do célebre episódio, ver Moser (1980), que passa em revista várias propostas de entendimento do episódio, discutindo inclusive leituras de poetas portugueses.

${ }^{29}$ Além das duas imitações que referimos aqui, lembremos a tradução em verso de outro quinhentista: André Falcão de Resende. Sobre as traduções que o português fez de Horácio, ver Hue (2012).

${ }^{30}$ Cf., por exemplo, Carm. 1.6, 1.19 e 4.15. A recusa à navegação é, por vezes, como em Carm. 4.15.1-4, o abandono da composição épica. Para a recusa da epopeia nas Odes de Horácio, ver Piccolo (2015, p. 260ss.), com bibliografia.

${ }^{31}$ É notável e já muito comentado o canto 4, por exemplo, em que os topoi da lírica aparecem na descrição do amor de Dido por Eneias. Para a presença da elegia e da tragédia, por exemplo, como "enriquecimento genérico", ver Harrison (2007, p. 208-14).

${ }^{32}$ A imitação inicial, que segue em boa parte a ordem das palavras, é inequívoca e bastante conhecida (Lus. 1.1.1-2): "As armas e os barões assinalados / que da Ocidental praia lusitana”, retomando Arma uirumque cano, Troiae qui primus ab oris. Ver, e.g., a edição de Dias (1916), que anota essa e outras alusões; ver também Blackmore (2012, p. 315 e n. 8). Porém, uma edição bem anotada, com as várias referências não só aos poetas latinos, ainda é um trabalho a se fazer, como Segurado e Campos (2000) realizou com a Ulisseia de Gabriel Pereira de Castro, imitador de Camões, que assim começa seu poema (1.1.1): "As armas e o varão que os mal seguros".

${ }^{33}$ Para a censura contra o inventor da navegação na poesia grega e latina, ver Fedeli (1980, p. 409-10).

${ }^{34}$ É possível ainda que o Carm. 1.3 de Horácio seja aludido em outro passo d'Os Lusíadas (6.82.4): "outros Acroceráunios infamados", retomando o v. 20: infamis scopulos, Acroceraunia? É possível, porém, que um trecho de Orlando Furioso de Ariosto (21.16.2) tenha feito a mediação para Camões: "L'Acrocerauno d'infamato nome".
} 
deixando ainda a palavra "fogo" na mesma posição em que se encontra ignem, em início de verso. Na sequência, há inovação por parte de Camões, pois introduz a figura de Faetonte (104.1-2: "Não cometera o moço miserando ${ }^{35}$ / O carro alto do pai ..."), novamente em perífrase. Por fim, com outra perífrase, menciona Dédalo ("o grande arquitector"). A expressão "o ar vazio" pode também vir de Horácio (v. 34: ... vacuum ... aera). Vale ressaltar, porém, algumas diferenças: o poeta latino menciona explicitamente Dédalo (v. 34: Daedalus) e não alude ao filho Ícaro, o que faz Camões (104.4: "um nome ao mar, e o outro fama ao rio”). Está, contudo, ausente no catálogo d'Os Lusíadas a descida aos infernos de Hércules. É notável, a nosso ver, essa ausência, pois em Antônio Ferreira, no catálogo das personagens que ultrapassaram limites (vv. 43-6), embora Hércules ali esteja, não se menciona a descida ao Hades, mas a colocação das Colunas de Hércules (vv. 45-6: “... outro o mar reparte / que por força rompeu"). ${ }^{36}$ As duas imitações quinhentistas também se aproximam ainda, afastando-se do modelo horaciano, pela utilização apenas de perífrases para mencionar as personagens mitológicas.

Diferentemente de Antônio Ferreira, Camões não parece ser modelo para as traduções de Elpino Duriense. No entanto, causou-nos certa estranheza a colocação das traduções parafrásticas de Horácio no interior da edição das Poesias Completas de Elpino ou Antônio Ribeiro dos Santos (1817, v. 3, p. 32-37). Importa-nos observar que na sequência (p. 38-51) há um conjunto de poemas dedicado às navegações portuguesas e ao descobrimento da América: o primeiro (p. 38-41), ao infante D. Henrique, em que emula "o grande cantor do excelso Gama" (v. 1); o segundo, a Cristóvão Colombo ("Colon”), descobridor da América (p. 41-3); o terceiro, a Vasco da Gama (p. 44-6), e um último, intitulado "Ao mesmo assunto", em que celebra os "Lusos Argonautas" (p. 47-51). Ao final do primeiro poema, ao infante D. Henrique, o poeta já anuncia os outros dois navegadores, Cristóvão Colombo e Vasco da Gama (vv. 57-60):

Dali, dali raiaram novas luzes, brilhantes mais que o lume das estrelas que guiaram depois a novos mundos

Colon, e o invicto Gama.

Ora, os poemas estão dispostos de maneira significativa, em sequência ordenada pelo autor a fim de celebrar as navegações e os descobrimentos. Se assim é, não parece sem importância a colocação das traduções parafrásticas, antecedendo-os: a tradução do Carm. 1.3 de Horácio (p. 32-4) é, como a fala do Velho do Restelo, um discurso contra o inventor da navegação e as viagens marítimas, desejando, porém, um percurso seguro; a segunda, do

\footnotetext{
${ }^{35}$ Note-se o latinismo com “miserando”. Para estudo dos latinismos n’Os Lusíadas, ver Silva (1931), muitos tirados da leitura de Virgílio.

${ }^{36}$ A substituição da descida aos infernos por ser motivada pelo contexto católico, sobretudo em Antônio Ferreira, que insere por fim uma prece a Deus. Seja como for, elimina-se um dos domínios que rodeiam o homem: o submundo, o que está abaixo da terra; preservam-se só os outros dois: o que rodeia a terra (o mar) e o que está acima dela (o céu).
} 
Carm. 2.14 (p. 35-7), é a lembrança da morte, que chega para todos (vv. 11-2: “... Príncipes potentes, / ou pobres lavradores") ${ }^{37}$ temendo em vão os perigos da navegação, entre outros (vv. 14-6): “.... em vão tememos / do Adriático mar, que se espedaça, / surcar as roucas ondas". ${ }^{38}$ Então, a mostrar a grandeza dos feitos dos navegantes, em seguida, compõe odes, emulando Camões, para o infante D. Henrique, Cristóvão Colombo e Vasco da Gama.

A fortuna, portanto, do Carm. 1.3 de Horácio $^{39}$ nas letras portuguesas passa, primeiramente, pelos poetas quinhentistas, inseridos na época das grandes navegações, em que, certamente, os debates sobre os perigos de se aventurar ao mar estavam em voga, os perigos de perder um ente querido - "por te cruzarmos, quantas mães choraram / quantos filhos em vão rezaram / quantas noivas ficaram por casar" -; esse passado, retratado, seja como louvor seja como maldição, é retomado pelos poetas posteriores, como Elpino Duriense, que, como seus antecessores, procura emular a tradição, tal como fizeram seus modelos em relação aos autores latinos. Se Elpino Duriense, no poema "À navegação portuguesa do infante D. Henrique”, diz (vv. 5-6): "Eu, que sou menos qu'ele [Camões], mor ainda / serei só por cantar teu nome ilustre", Camões, por sua vez, no início d'Os Lusíadas, afirma, orgulhoso, emulando a tradição grega e latina (1.3):

Cessem do sábio Grego e do Troiano

As navegações grandes que fizeram;

Cale-se de Alexandre e de Trajano

A fama das vitórias que tiveram;

Que eu canto o peito ilustre Lusitano,

A quem Neptuno e Marte obedeceram:

Cesse tudo o que a Musa antiga canta,

Que outro valor mais alto se alevanta.

\section{REFERÊNCIAS}

ACHCAR, F. Lirica e lugar-comum. Alguns temas de Horácio e sua presença em português. São Paulo: Edusp, 1994.

BLACKMORE, J. The shipwrecked swimmer: Camões's maritime subject. Modern Philology, v. 109, p. 312-325, 2012.

\footnotetext{
${ }^{37}$ Trecho que traduz os vv. 11-2 do original latino: “sive reges / sive inopes erimus coloni”. Note-se a adjetivação acrescida para "príncipes".

${ }^{38}$ Aqui refaz parte da quarta estrofe do Carm. 2.14, traduzindo, em particular, o v. 14: "fractisque rauci fluctibus Hadriae".

${ }^{39}$ O próprio Horácio, por sua vez, modelo para longa série de poetas, emula outros no Carm. 1.3, como Calímaco fr. 400 Pf. e possivelmente Meléagro (AP 12.52.2), entre os helenísticos. Porém, se a expressão animae dimidium meae (v. 8), por um lado, foi tomada de Calímaco (AP 12.73.1) e/ou

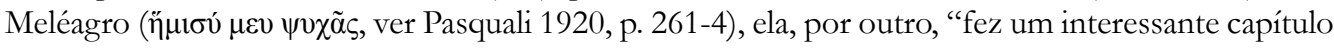
da história literária" (Nisbet-Hubbard 1970, ad loc.).
} 
O CARM. 1.3 DE HORÁCIO, DUAS TRADUÇÕES DE ELPINO DURIENSE E DUAS IMITAÇÕES

QUINHENTISTAS

BOYLE, A. J. Seneca. Medea. Oxford: Oxford University Press, 2014.

CAIRNS, F. Generic composition in Greek and Roman poetry. Edinburgh: Edinburgh University Press, 1972.

COSTA, C. D. N. Seneca. Medea. Oxford: Clarendon Press, 1973.

CURTIUS, E. R. Literatura europeia e Idade Média Latina. Tradução de Teodoro Cabral e Paulo Rónai. São Paulo: Edusp, 2013.

DIAS, A. E. S. Os Lusíadas de Camões comentados por Augusto Epifânio da Silva Dias. $2^{a}$ ed. Porto: Companhia Portuguesa, 2016. 2 t.

DURIENSE, E. A brica de Q. Horacio Flacco, poeta romano, trasladada literalmente em verso português por Elpino Duriense. Lisboa: Impressão Régia, 1807. 2 t.

DURIENSE, E. Poesias de Elpino Duriense. Lisboa: Impressão Régia, 1817. t. 3.

EARLE, T. F. António Ferreira. Poemas Lusitanos. Lisboa: Fundação Calouste Gulbenkian, 2000.

FEDELI, P. Sesto Properzio. Il primo libro delle elegie. Firenze: Leo S. Olschki, 1980.

FRAENKEL, E. Horace. Oxford: Clarendon Press, 1957.

HARRISON, S. J. Generic Enrichment in Vergil \& Horace. Oxford: Oxford University Press, 2007.

HASEGAWA, A. P. Duas traduções portuguesas do livro dos Epodos de Horácio no séc. XVIII. In CORREAA, P. C.; MARTINHO, M.; MACEDO, J. M.; HASEGAWA, A. P. (ed.). Hyperboreans. Essays in Greek and Latin poetry, philosophy, rhetoric and linguistics. São Paulo: Humanitas, 2012, p. 131-46.

HASEGAWA, A. P. Tradução de Odes de Horácio com matéria erótica expurgadas por Elpino Duriense. Translatio, v. 10, p. 3-29, 2015.

HASEGAWA, A. P. Mercúrio rouba a voz e o lugar de Apolo no carm.1. 10 de Horácio. PhaoS, v. 17, n. 1, p. 83-100, 2017.

HINE, H. M. Seneca. Medea. Warminster: Aris \& Phillips, 2000.

HUE, S. M. André Falcão de Resende, tradutor de Horácio. In FRAGA, M. C; LUZ, J. L. B.; MARTINS, J. C. O; SILVA, J. A. (ed.). Camões e os contemporâneos. Braga: CIEC, 2012, p. 365-375.

MAYER, R. Horace. Odes, Book I. Cambridge: Cambridge University Press, 2012.

McKEOWN, J. C. Ovid: Amores. Text, prolegomena and commentary in four volumes. Leeds: Francis Cairns, 1998. v. 3.

MINARINI, A. Lucidus ordo. L'architettura della lirica orażiana (libri I-III). Bologna: Pàtron Editore, 1989. 
MOSER, G. M. What did the Old Man of the Restelo mean? Luso-Brazilian Review, v. 17, p. 139-151, 1980.

NÉMETI, A. Lucio Anneo Seneca. Medea. Pisa: Edizione ETS, 2003.

NISBET, R. G. M. The word order of the Odes. In ADAMS, J. N.; MAYER, R. G. (ed.). Aspects of the Language of Latin Poetry. Oxford: Oxford University Press, 1999, p. 135-154. In LOWRIE, M. (ed.). Oxford Readings in Classical Studies. Horace: Odes and Epodes. Oxford: Oxford University Press, 2009, p. 378-400.

NISBET, R. G. M.; HUBBARD, M. A Commentary on Horace, Odes, Book I. Oxford: Clarendon Press, 1970.

OLIVA NETO, J. A. Introdução: Bocage e a tradução poética no século XVIII. In OVÍDIO. Metamorfoses. Tradução e notas de Bocage. São Paulo: Hedra, 2017, p. 9-33.

PASQUALI, G. Orazio lirico. Firenze: Felice Le Monnier, 1920.

PICCOLO, A. O Arco e a lira: modulações da épica homérica nas Odes de Horácio. 2015. Tese (Doutorado em Linguística) - Universidade Estadual de Campinas, Instituto de Estudos da Linguagem, Campinas, SP, 2015.

PUTNAM, M. C. J. Statius Siluae 3.2: reading travel. Illinois Classical Studies, v. 42, p. 83-139, 2017.

ROCHA PEREIRA, M. H. M. Temas clássicos na poesia portuguesa. Lisboa: Editorial Verbo, 1972. ROMANO, E. Q. Orazio Flacco. Le Opere I (le Odi, il Carme secolare, gli Epodi). Roma: Instituto Poligrafico e Zecca dello Stato, 1991. t. 2.

SEGURADO e CAMPOS, J. A. Gabriel Pereira de Castro. Ulisseia on Lisboa edificada. Lisboa: Fundação Calouste Gulbenkian, 2000.

SILVA, C. E. C. S. Ensaio sobre os latinismos dos Lusíadas. Coimbra: Imprensa da Universidade, 1931.

SOARES, N. N. C. Mostras de sentido no fluir do tempo: estudos de Humanismo e Renascimento. Coimbra: Imprensa da Universidade de Coimbra, 2018.

TARRANT, R. A new critical edition of Horace. In HUNTER, R.; OAKLEY, S. P. Latin literature and its transmission. Papers in honour of Michael Reeve. Cambridge: Cambridge University Press, 2019, p. 291-321.

VASCONCELLOS, P. S. Duas odes horacianas e uma imitação camoniana. Classica, v. 15/16, p. $233-247,2002 / 3$.

WILLIS, C. António Ferreira, T. F. Earle, Poemas Lusitanos. Modern Language Review, v. 99, n. 3, p. 821-822, 2004. 